\title{
Obituary
}

Prof. Albert Calmette, For. Mem. R.S. A LBERT CALMETTE, sub-director of the Pasteur A Institute, who died on October 29, 1933 after a short illness, was born at Nice on July 12, 1863. After graduation, he entered the medical service of the navy and spent seven years in Eastern waters. As a naval surgeon, he became interested in the numerous hygienic problems of France's colonial possessions. In 1889 he was transferred to the new colonial medical service and was given permission to go to the Pasteur Institute. There he came under the influence of Pasteur, and took Roux's course of lectures in bacteriology and became one of his most enthusiastic pupils. His progress was so rapid that the next year he was chosen by Pasteur to proceed to Saigon to found the first of the daughter Pasteur institutes.

At Saigon, Calmette was occupied with the study of cholera and bacillary and amœebic dysenterics. It was here, too, that he first became interested in snake venoms. The number of deaths from cobra-bite was serious and the director of the new institute was appealed to for help by the administration.

In 1893 Calmette returned to France and continued his work on the action of cobra venom. This was followed up by experiments to ascertain whether the serum of an animal immunised against the venom contained anti-toxins and could be exploited for treatment. Sewall had shown that immunity followed repeated small injections of the venom of the rattlesnake, and Behring had a few years previously established the anti-toxic value of the serum of animals treated in a similar manner with the toxins of the tetanus and diphtheria bacillus. It seemed, therefore, not unlikely that an anti-toxic immunity would be aroused by the injection of snake venom.

Before the end of 1894 Calmette was successful in demonstrating that by patiently immunising horses with increasing doses of cobra venom they accumulated sufficient antitoxin in their serum for the latter to be used as a remedy for snake-bite. As most venoms were similar in their actions, Calmette at first supposed that serum prepared by injecting cobra venom would be of value to counteract the effects of the poisons of other kinds of snake. He was rather obstinate in adhering to this opinion in the face of experimental evidence from Australia, India and Brazil that such was not the case but that anti-venoms were highly specific.

In 1895, Calmette's enthusiasm and organising ability was again taken advantage of and he was chosen to establish a Pasteur Institute for the north of France at Lille. The new institute was to be a subsidiary centre for anti-rabic inoculation and the preparation of diphtheria antitoxin and vaccine lymph. Under Calmette's guidance, it soon became an active centre of research. From the point of view of sanitation, the industrial town of Lille was not progressive. Its water supply and methods for the disposal of sewage were unsatisfactory. The incidence of tuberculosis was high and invalidism from hook-worm in the neighbouring coal-mines was serious. Calmette, who was appointed professor of hygiene a few years after his arrival, worked vigorously to improve the sanitary condition of the town. $\mathrm{He}$ instituted investigations into the bacterial treatment of sewage and various methods for the purification of water supplies. He was successful in inducing the municipal authorities to undertake some measure of improvement. He made a useful research into hook-worm, and his method for combating this disease in miners is that now usually followed elsewhere.

How to diminish the damage to health and life caused by infection with the tubercle bacillus was a more serious problem. Calmette established a tuberculosis dispensary, the first in France, for the early diagnosis of phthisis and for the education of patients in habits to minimise the familial spread of the disease. He was instrumental in providing a sanatorium for early, and a colony for advanced, cases of the disease. These measures, however, did not strike at the root of the matter and the idea of attacking the problem by some immunological procedure was always present in his mind. All efforts to produce resistance by the inoculation of killed cultures of the tubercle bacillus having proved unsatisfactory, he turned his attention to the possibility of employing a living attenuated culture as Pasteur had done in the case of anthrax. His goal was to produce a strain of the bacillus so much deprived of its virulence that it would not produce tuberculosis when introduced into animals but only a mild illness, recovery from which inevitably occurred. It was hoped that by this experience the body would acquire the power of dealing satisfactorily with a subsequent infection by virulent microbes.

In 1903, in collaboration with his assistant Guérin, Calmette began the researches which ultimately resulted in the now famous strain of bovine tubercle bacilli designated B. C. G. (Bacillus Calmette Guérin). This strain was produced by successive propagation of an ordinary bovine type of bacillus on potato soaked in bile. Its stabilisation took thirteen years, during which 230 successive cultivations were made. At the end of this time, the strain was found to be incapable of producing tuberculosis in animals and to remain devoid of this power as long as it was cultivated on the bile-media.

By 1914 the experiments of Calmette and Guérin had convinced them that cultures of B. C. G. could be used to induce resistance to tuberculosis in cattle. At this stage, their researches were perforce suspended by the outbreak of War. During the occupation of Lille, Calmette came under suspicion because he kept numbers of 
pigeons in his laboratory. He suffered regrettable indignities at the hands of the military authorities and his wife was removed to Germany as a hostage. During this unhappy period, he occupied himself writing an interesting book on the pathology of tuberculosis, in which he presented his observations and developed his theory of the nature of acquired resistance to the disease.

On the death of Metchnikoff in 1917, Calmette was elected sub-director of the Pasteur Institute but did not undertake the duties of this office until after the War. At Paris he continued his researches on protection against infection by the tubercle bacillus with increased fervour and enlarged opportunities.

To understand the subsequent progress of these researches it is necessary to epitomise his conception of the means by which individuals acquire their resistance to the tubercle bacillus. Both evidence from post-mortems and the results of the skin reaction of von Pirquet to tuberculin indicate that the majority of individuals by fifty years of age have at some time in their life been infected, although they may not have shown symptoms of tuberculosis. Calmette believed, and had experimental evidence to support his belief, that a very small number of infecting bacilli is not, in most individuals, followed by manifest tuberculosis and is recovered from, leaving the body more capable of resisting a subsequent dose. In this manner by a succession of small infections an immunity is acquired.

Immunisation by chance is, however, a highly dangerous way of attaining resistance, for, at any time, the dose may be sufficiently large to break down the individual's resistance and tuberculosis ensue. Calmette therefore advocated that the wise procedure would be to accustom the body to resist invasion by the tubercle bacillus by giving its immunological mechanisms opportunities to obtain practice with an innocent tubercle bacillus before the nearly inevitable inroad of a virulent one took place, much as it is well to acquire expertness as a toreador with de-horned cattle. To do this he suggested that young babies should be given minute doses of his attenuated B. C. G. culture by mouth before they have had an opportunity to ingest virulent bacilli, a procedure he calls 'premunition'.

In 1922 Dr. Weill-Hallé treated 314 infants, the progeny of tuberculous mothers. The treatment was inoffensive and a comparison of the tuberculosis rate amongst treated and untreated infants from similar environment was deemed to be promising. The treatment was begun 3 days after birth to minimise the chances of the infants being infected by virulent bacilli from their mothers prior to receiving the strain B.C.G. Since then upwards of a million babies have been treated in France and elsewhere, and apart from the tragedy at Lubeck, where by carelessness at the hospital, some 250 infants were fed a dose of a culture of virulent human tubercle bacilli by mistake and 73 died, no untoward happening has been recorded. At the present time some 150,000 infants are treated annually in France alone and the council of the Pasteur Institute has erected a vast building for the preparation and distribution of cultures of B. C. G. all over the world.

Unfortunately, the resistance obtained from one treatment is not permanent and has to be repeated after one or two years. This makes it more difficult accurately to assess the results of the treatment for some years to come. The figures recorded are susceptible of statistical criticism, but the numerous practitioners who have employed the treatment are very generally convinced that it is followed by a decline in the incidence of tuberculosis and also by a diminution of the general mortality during the early years of life. To what extent this promise is justified will emerge in a few years, when the after-history of the million infants already treated is known. Whatever this verdict is, Calmette's endeavours to mitigate the ravages of tuberculosis will remain the magnificent effort of a man who devoted his life to the pursuit of science for the service of mankind. C. J. M.

\section{Mr. J. B. HobLyN}

By the death on December 24 of John Bright Hoblyn, in his fifty-fourth year, the automobile engineering industry has lost one of its best known scientific personalities. During his eighteen years' association with Messrs. Vauxhall Motors Ltd, of Luton, he had become a prominent figure in the fields of metallurgy and petroleum technology, and his ready flow of witty and pungent speechand, on occasion, of scathing criticism-made him an attractive lecturer and debater.

An old student of the Royal College of Science, Mr. Hoblyn was for eleven years science master at Luton Modern School. In 1915 he accepted an invitation to join Vauxhall Motors Ltd. as chief chemist and metallurgist, and he promptly applied himself to the chemical and metallurgical problems of automobile engineering. His publications included three papers of outstanding importance to the industry, dealing respectively with the heat treatment of steels, the oxidation of lubricating oils and the development of aluminium alloys for automobile construction. His work on lubricating oils opened up a new avenue in the testing technique of these products.

For several years past Mr. Hoblyn had been chairman of the committee set up by the Institution of Automobile Engineers for the rationalisation of automobile steel specifications, and at the time of his death he had almost seen the completion of his labours in this field.

L. B. H.

WE regret to record the death of Prof. J. E. G. de Montmorency, Quain professor of comparative law in the University of London in 1920-32, whose studies of primitive law formed valuable contributions to anthropology, on March 9, aged sixty-seven years. 